\title{
Hydrophobic dipeptide crystals: a promising Ag-free class of ultramicroporous materials showing argon/oxygen adsorption selectivity
}

\author{
R. Afonso, ${ }^{a, b}$ A. Mendes ${ }^{b}$ and L. Gales ${ }^{a, c, *}$
}

The adsorption isotherms of nitrogen, oxygen and argon in four VA-class hydrophobic dipeptides are presented. Isotherms were determined at 5,20 and $35^{\circ} \mathrm{C}$, for a pressure range of 0-6 bar. Under these conditions, adsorption is still in the Henry region. For all materials and temperatures, the sequence of preferential adsorption is $\mathrm{Ar}>\mathrm{O}_{2}>\mathrm{N}_{2}$, a highly abnormal result. At $5{ }^{\circ} \mathrm{C}$, the dipeptide with the smallest pores, $\mathrm{VI}$, has $\mathrm{Ar} / \mathrm{O}_{2}$ adsorption equilibrium selectivities up to 1.30, the highest ever measured in $\mathrm{Ag}$-free adsorbents. Gas uptakes, at 1 bar and $20^{\circ} \mathrm{C}$, are $\sim 0.05 \mathrm{~mol} \cdot \mathrm{kg}^{-1}$, very low relative values that are partially explained by the low porosity of the solids $(<10 \%)$. The significance of these results for the development of new materials for the process of $\mathrm{O}_{2}$ generation by pressure swing adsorption (PSA) is discussed. The results indicate some of the structural and chemical properties that prospective Ag-free adsorbents should have in order to have $\mathrm{Ar} / \mathrm{O}_{2}$ selectivity; hydrophobic pores, less than $0.5 \mathrm{~nm}$-wide, and porosity of, at least, $20 \%$.

\section{Introduction}

Crystalline hydrophobic dipeptides of the VA-class ${ }^{1,2}$ are a type of ultramicroporous solids that has received considerable attention in recent years ${ }^{3-6}$. The structure of these molecular crystals is stabilised by $\mathrm{H}$-bonds and hydrophobic interactions, being essentially the same for all VA-class dipeptides. This crystal structure displays an array of identical, parallel unidimensional micropores ${ }^{2,7}$. The pore walls are formed by the aliphatic side-chains of the dipeptides, making the pores highly hydrophobic ${ }^{1}$. Different side-chain combinations create slightly different crystal structures, with different pore sizes ${ }^{1}$. The micropores are helical and have an approximately circular crosssection, somewhat uniform throughout the unit cell ${ }^{4,7}$. Nominal, average pore sizes of VA-class dipeptide crystals range from $0.37 \mathrm{~nm}$ to $0.50 \mathrm{~nm}^{2,7}$.

Crystal porosity has been proven several times, by determination of adsorption isotherms ${ }^{4,8,9}$, and through ${ }^{129} \mathrm{Xe}$ NMR ${ }^{3,5-7,10,11}$. Additionally, when embedded in solvents of different colours, the crystals also become uniformly coloured ${ }^{12}$, indicating thorough solvent permeation into the pores. Recent NMR experiments have also shown that the pores in VA and AV dipeptide crystals typically span the entire crystal length ${ }^{6}$. Dipeptide crystals thus have incredibly open pores. Moreover, the supramolecular framework of the dipeptide crystals is very flexible, allowing penetration of guests bigger than the guest-free pore ${ }^{8,13,14}$. This observation is supported by vibration spectroscopy ${ }^{15}$ and ${ }^{129} \mathrm{Xe}$ NMR ${ }^{3}$ studies. For guest molecules smaller than the pore, there has yet to be demonstrated any clear effect resulting from framework flexibility ${ }^{4}$.

The relatively few gas adsorption studies performed with VA-class dipeptides have yielded some notable results, such as high $\mathrm{H}_{2}$ adsorption capacities ${ }^{9}$, high $\mathrm{CO}_{2} / \mathrm{CH}_{4}$ selectivities ${ }^{4}$ and Xe adsorption in pores nominally too small for that to happen ${ }^{8}$. In this article, we report the adsorption isotherms and heats of adsorption of $\mathrm{Ar}, \mathrm{O}_{2}$ and $\mathrm{N}_{2}$ in four crystalline dipeptides. The four dipeptides used have the smallest pores of the VA-class; VI, IA, IV and VV, having, respectively, $0.370,0.374,0.390$ and $0.439 \mathrm{~nm}$ average crystallographic diameters ${ }^{2}$, corresponding, respectively, to porosities of 5.7, 6.0,6.3 and $8.3 \%$ (as determined from the crystal structure) ${ }^{7}$. The adsorbents show inverted $\mathrm{Ar} / \mathrm{O}_{2}$ selectivity, a highly abnormal result, extremely interesting in the context of the very important industrial process of $\mathrm{O}_{2}$ production by pressure swing adsorption (PSA).

Industrial $\mathrm{O}_{2}$ production relies almost exclusively on air-separation processes ${ }^{16,17}$. One of these, PSA, is a cyclic chromatographic separation process ${ }^{18}$, which, in the last four decades, has steadily been displacing cryogenic 
distillation as the process of choice for $\mathrm{O}_{2}$ production, in an increasing number of conditions ${ }^{16,17}$. Presently, improvement of the process of air separation by PSA depends mainly on the development of new adsorbent materials, with greater working capacities ${ }^{19,20}$ and selectivities; this is especially the case for $\mathrm{O}_{2}$, which is particularly hard to separate from Ar.

PSA production of $\mathrm{O}_{2}$ with up to $95 \%$ purity is done using zeolites with $\mathrm{N}_{2} / \mathrm{O}_{2}$ selectivities of 2 to $10^{16,21,22}$. In these adsorbents, it is very common that the adsorption isotherms of $\mathrm{O}_{2}$ and $\mathrm{Ar}$ are close ${ }^{23,24}$, causing the $\mathrm{Ar} / \mathrm{O}_{2}$ ratio to remain unchanged throughout the column, approx. $1 / 20$ (the same as in air), thus limiting the $\mathrm{O}_{2}$ purity achievable to $95 \%$. Separation of $\mathrm{O}_{2}$ and Ar for high-purity $(>95 \%) \mathrm{O}_{2}$ generation is usually done using a kinetically selective carbon molecular sieve (CMS) adsorbent, where $\mathrm{O}_{2}$ has a much higher diffusivity than $\mathrm{Ar}$ and $\mathrm{N}_{2}$; that is, the adsorbent has $\mathrm{O}_{2} / \mathrm{Ar}$ and $\mathrm{O}_{2} / \mathrm{N}_{2}$ kinetic selectivities. This separation can be performed before ${ }^{25}$ or after ${ }^{26}$ removing the bulk of $\mathrm{N}_{2}$ with another PSA unit, using a zeolite adsorbent. For technical reasons ${ }^{22-24,27}$, the optimal situation combines initial $\mathrm{N}_{2}$ removal followed by $\mathrm{Ar} / \mathrm{O}_{2}$ separation based on an adsorbent with $\mathrm{Ar} / \mathrm{O}_{2}$ selectivity (instead of $\mathrm{O}_{2} / \mathrm{Ar}$ ). Enormous efforts have been directed at finding materials displaying this property ${ }^{22,24}$.

Adsorbents that preferentially adsorb $\mathrm{Ar}$ over $\mathrm{O}_{2}$ are rare, and the ones that do exist have marginal selectivities. The first Ar-selective adsorbent discovered was silver-exchanged mordenite, Ag-mordenite, with an $\mathrm{Ar} / \mathrm{O}_{2}$ selectivity of $1.13^{28}$. The potential for PSA separation of $\mathrm{Ar} / \mathrm{O}_{2}$ mixtures of Ag-mordenite was immediately recognised ${ }^{23}$. In the next two decades, several articles and patents followed, describing adsorbents with greater selectivities and capacities, as well as more efficient $\mathrm{O}_{2}$-generating PSA processes ${ }^{20,22,24,27,29-32}$.

The highest $\mathrm{Ar} / \mathrm{O}_{2}$ adsorption selectivity value ever measured was 1.65, on a Ag-exchanged zeolite ZSM-5, closely followed by that of a Ag-exchanged zeolite A, 1.63, both at atmospheric pressure ${ }^{30}$. Adsorbents used in PSA or gas chromatography experiments are all also Ag-exchanged zeolites 22-24, 27, 28, 32. These have the additional advantage of having extremely high $\mathrm{N}_{2} / \mathrm{O}_{2}$ selectivities $(>10){ }^{20}$. However, incorporation of silver also makes these materials quite expensive, greatly hindering their usage. Discovery of Ag-free porous materials displaying the desired selectivities is thus of great commercial and technical interest.

The overwhelming majority of porous solids adsorb more $\mathrm{O}_{2}$ than $\mathrm{Ar}^{20,22,33,34}$. Metal-organic frameworks (MOFs) typically have the preferential adsorption sequence $\mathrm{O}_{2}>\mathrm{Ar}>\mathrm{N}_{2}{ }^{35},{ }^{36}$, zeolites have $\mathrm{N}_{2}>\mathrm{O}_{2}>\mathrm{Ar}{ }^{37,38}$ and carbon-based materials display the two situations with similar frequency ${ }^{39,40}$. We were able to find a single case of an adsorbent having an $\mathrm{O}_{2}>\mathrm{N}_{2}>$ Ar sequence of preferential adsorption ${ }^{41}$. To date, to the best of our knowledge, only six known Ag-free porous materials show $\mathrm{Ar} / \mathrm{O}_{2}$ equilibrium selectivity; MIL-53(Al) (the "breathing" MOF) ${ }^{42}$, mordenite (zeolite) ${ }^{30,43}$, a CMS ${ }^{44}$, ZSM-5 (zeolite) ${ }^{30,45}$, a polymer of intrinsic microporosity ${ }^{46}$ and an activated carbon ${ }^{47}$, having equilibrium $\mathrm{Ar} / \mathrm{O}_{2}$ selectivities of, respectively, 1.26, 1.12, 1.11, 1.08, 1.09 and 1.06. Out of the six, the first four adsorb in the sequence $\mathrm{N}_{2}>\mathrm{Ar}>\mathrm{O}_{2}$, the last two $\mathrm{Ar}>\mathrm{O}_{2}>\mathrm{N}_{2}$ and not a single instance of adsorption in the sequence $\operatorname{Ar}>\mathrm{N}_{2}>\mathrm{O}_{2}$. The reason for this exceptional behaviour was not addressed in any case. This limited number and inexistence of appropriate explanations of the selection mechanism prevent the design of strategies for the development/discovery of new $\mathrm{Ag}$-free $\mathrm{Ar} / \mathrm{O}_{2}$ selective adsorbents.

The dipeptide crystals tested for this work have the order of adsorption $\mathrm{Ar}>\mathrm{O}_{2}>\mathrm{N}_{2}$, with a maximum $\mathrm{Ar} / \mathrm{O}_{2}$ selectivity of 1.30 , at $5{ }^{\circ} \mathrm{C}$, for VI. A discussion of the reasons for these abnormal results and their significance in the context of the development of new materials for air separation by PSA is given.

\section{Experimental}

Excess adsorption isotherms of $\mathrm{N}_{2}, \mathrm{O}_{2}$ and Ar were determined for crystalline samples of four dipeptide crystals, VI, IA, IV and VV, at $5{ }^{\circ} \mathrm{C}, 20^{\circ} \mathrm{C}$ and $35^{\circ} \mathrm{C}$. Samples of dipeptides VI, IA, IV and VV were purchased from Bachem. Samples are received as a crystalline white powder ${ }^{9}$, which were regenerated overnight, under vacuum $(<1 \mathrm{mbar})$, at $70^{\circ} \mathrm{C}$, before being used in the adsorption experiments. The adsorption isotherms were determined using the volumetric method. This method is based on measuring the variation of pressure of the gas after an expansion between two tanks of known volume, one of which contains the adsorbent sample. Using an appropriate equation of state for the gas phase (the Peng-Robinson equation was used in this work) and performing a mass balance, it is possible to determine the total amount adsorbed. The sorbate concentration is determined by dividing this value by the sample mass. The sample tank and feed tank volumes were, respectively, $13.32 \mathrm{~mL}$ and $54.37 \mathrm{~mL}$. The masses of VI, IA, IV and VV used were, respectively, $2.4927 \mathrm{~g}, 1.0144 \mathrm{~g}, 2.4131 \mathrm{~g}$ and $1.0064 \mathrm{~g}$. The pressure transducer used was a WIKA P-30, 0-6 bar (accuracy of 0.1 \% FS). The temperature of the system was controlled through immersion in a Huber CCE-K12 thermostatic bath. Swagelok tubing and valves were used to connect the tanks, the gas feed and the 
exhaust. Pressures below 1 atm were achieved using a Vacuubrand RZ 2.5 vacuum pump. Alphagaz 1 gases, supplied by Air Liquide, were used, with purities of $99.99965 \%$ for $\mathrm{O}_{2}$ and $99.99945 \%$ for the remaining ones.

\section{Results and Discussion}

\section{Adsorption isotherms and monocomponent selectivities}

The adsorption isotherms of $\mathrm{Ar}, \mathrm{O}_{2}$ and $\mathrm{N}_{2}$ in the crystalline powder of dipeptides VI, IA, IV and VV, at $20^{\circ} \mathrm{C}$, are shown, grouped by material, in

Fig. 1. Graphs of isotherms at $5{ }^{\circ} \mathrm{C}$ and $35^{\circ} \mathrm{C}$ and grouped by gas species are presented in Sup. Inf.. Adsorption takes place, essentially, in the Henry region, with isotherms being only slightly bent. $80 \%$ of adsorption took place, at least, in the first $30 \mathrm{~s}$, and very often in the first 5-10 s. The dipeptide crystals in the powder are 1-50 $\mu \mathrm{m}$ in length. Desorption isotherms were also determined in every case (not shown) and hysteresis was never detected. $\mathrm{N}_{2}$ adsorption isotherms have been determined before, for $25^{\circ} \mathrm{C}^{4}$, and are similar to the ones here reported.

The adsorption isotherms were numerically fitted with the Volmer equation,

where

$$
b P=\frac{\theta}{1-\theta} \exp \left(\frac{\theta}{1-\theta}\right)
$$

and

$$
b=\frac{K_{H}}{n_{\max }}
$$

$$
\theta \equiv \frac{n}{n_{\max }}
$$

$b$ is the affinity constant, $P$ is the pressure, $\theta$ is the amount adsorbed relative to the maximum that can be adsorbed, $K_{H}$ is Henry's constant, $n$ is the adsorbed concentration and $n_{\max }$ is the maximum adsorbed concentration. The parameters fitted were $n_{\max }$ and $b$. Both excess and absolute adsorption equilibrium values were determined. Fitting results are shown in Sup. Inf..

A previous report ${ }^{4}$ showed that $\mathrm{CO}_{2}$ adsorption in VA-class dipeptides has a mixed localised/mobile character. However, the $\mathrm{N}_{2}$ and $\mathrm{O}_{2}$ molecules and the Ar atom are much shorter and more electronically homogeneous than the $\mathrm{CO}_{2}$ molecule. This leads us to think that the $\mathrm{N}_{2}, \mathrm{O}_{2}$ and $\mathrm{Ar}$ adsorbed phases must have a predominantly mobile character, being thus better represented by the Volmer rather than the Langmuir equation. Nonetheless, the Henry constants determined for both equations, through Eq. (2), are essentially the same, with only $b$ and $n_{\max }$ varying. This was to be expected, since both equations reduce to the Henry equation at low loadings. 

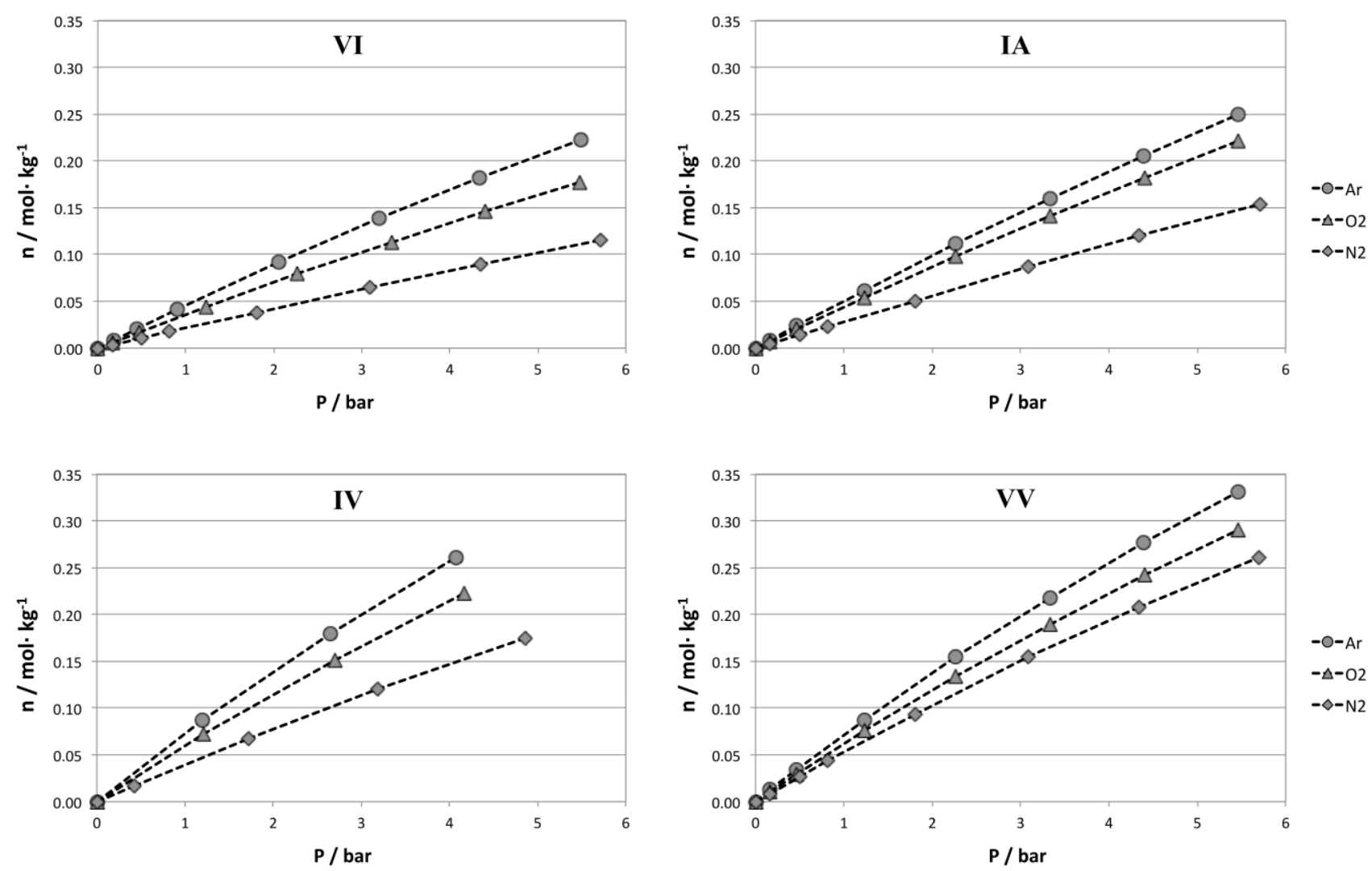

Fig. 1 Excess adsorption isotherms ${ }^{48}$ of $\mathrm{Ar}, \mathrm{O}_{2}$ and $\mathrm{N}_{2}$ on $\mathrm{VI}, \mathrm{IA}, \mathrm{IV}$ and $\mathrm{VV}$, at $20^{\circ} \mathrm{C}$, grouped per material.

Adsorption trends are similar for the four dipeptides. The adsorbed concentration varies according to the sequence $\operatorname{Ar}>\mathrm{O}_{2}>\mathrm{N}_{2}$, for all cases. This is a highly unusual sequence, as discussed in the Introduction, having been observed only in two other adsorbents ${ }^{46,47}$. It is noteworthy that both of these cases refer to fully organic microporous materials, like the crystalline dipeptides considered here. For the three gas species, the amount adsorbed increases with pore size/porosity, i.e., $\mathrm{VI}<\mathrm{IA}<\mathrm{IV}<\mathrm{VV}$. This increase is not even, being greater for the least adsorbed species, $\mathrm{N}_{2}$, and smallest for the most adsorbed species, Ar (see Sup. Inf.). A similar overall trend of increased adsorption with pore size was also observed for $\mathrm{CO}_{2}$ and $\mathrm{CH}_{4}{ }^{4}$.

Fig. 2 plots $\mathrm{Ar} / \mathrm{O}_{2}$ and $\mathrm{O}_{2} / \mathrm{N}_{2}$ monocomponent selectivities (i.e., concentration ratios) as a function of pressure, for VI, at the three temperatures used. Monocomponent adsorption selectivities were determined from the adsorption results, with adsorption isotherms being expressed by data-fitted Volmer equations. The graphs for IA, IV and VV are shown in the Sup. Inf., since they display the exact same trends, with somewhat smaller values. The monocomponent selectivity curves have the typical shape for two gases displaying Type I adsorption isotherms; an asymptotic decline to the ratio of capacities. Since, for the pressure range tested, the isotherms are still close to the Henry region, this decline is moderate. Selectivity variation with temperature is very dependent on pressure, with curves for different temperatures crossing in the graph. Still, at close to vacuum (Henry) conditions, the selectivity always decreases with temperature, as a consequence of the greater heat of adsorption of the most adsorbed gas. This is not always the case for the other three dipeptides, as will be later discussed, and is apparent in their respective graphs (see Sup. Inf.).

The vacuum (Henry) Ar/ $\mathrm{O}_{2}$ and $\mathrm{O}_{2} / \mathrm{N}_{2}$ selectivities of the four dipeptides, at $20^{\circ} \mathrm{C}$, are plotted against pore size in Fig. 3. The selectivities of VI, IV and VV form an approximately linear, descending trend with increasing pore size, reflecting the importance of confinement in determining the unusual sequence of intensity of adsorption. IA is a clear outlier, falling significantly below the trend line, especially for $\mathrm{Ar} / \mathrm{O}_{2}$. The linearity of the trend may be just a coincidence, but it is interesting to notice that, if it was to continue, the $\mathrm{Ar} / \mathrm{O}_{2}$ and $\mathrm{O}_{2} / \mathrm{N}_{2}$ selectivities would reach 1 at $\sim 0.55 \mathrm{~nm}$ and $\sim 0.46 \mathrm{~nm}$, respectively. These are still very small pore sizes, again showing the paramount importance of pore size in determining the unordinary sequence of adsorption. 
The well-established and consistent kinetic selectivities of atmospheric gases in CMSs ${ }^{37,39,44,49,50}$ show that the relative size of the three species, in the context of adsorption and diffusion, in atomic-sized pores of hydrophobic materials, is $\mathrm{N}_{2}>\mathrm{Ar}>\mathrm{O}_{2}$. The Lennard-Jones atomic diameter of $\mathrm{Ar}$ and minimum molecular widths of $\mathrm{N}_{2}$ and $\mathrm{O}_{2}$ have been estimated as $0.32,0.34$ and $0.31 \mathrm{~nm}$, respectively ${ }^{51}$, all clearly below the pore sizes of the dipeptide crystals used.

Studies performed using ${ }^{129} \mathrm{Xe} N \mathrm{NM}^{3,10}$ showed that sorbate-sorbent interactions in dipeptide crystal micropores are maximised when pore-size precisely matches sorbate size, decreasing for bigger and smaller pores. This is exactly the same behaviour as that observed for hard materials ${ }^{51}$. We thus think that the size sequence of the three gases established from CMS adsorption experiments is also valid for dipeptide crystals. A lot has also been made of the possibility of using the chiral pores of dipeptide crystals to separate enantiomers ${ }^{2,8}$. However, in the context of adsorption of symmetrical molecules/atoms smaller than the pores, there is not reason to think that pore helicity and chirality influence adsorption.
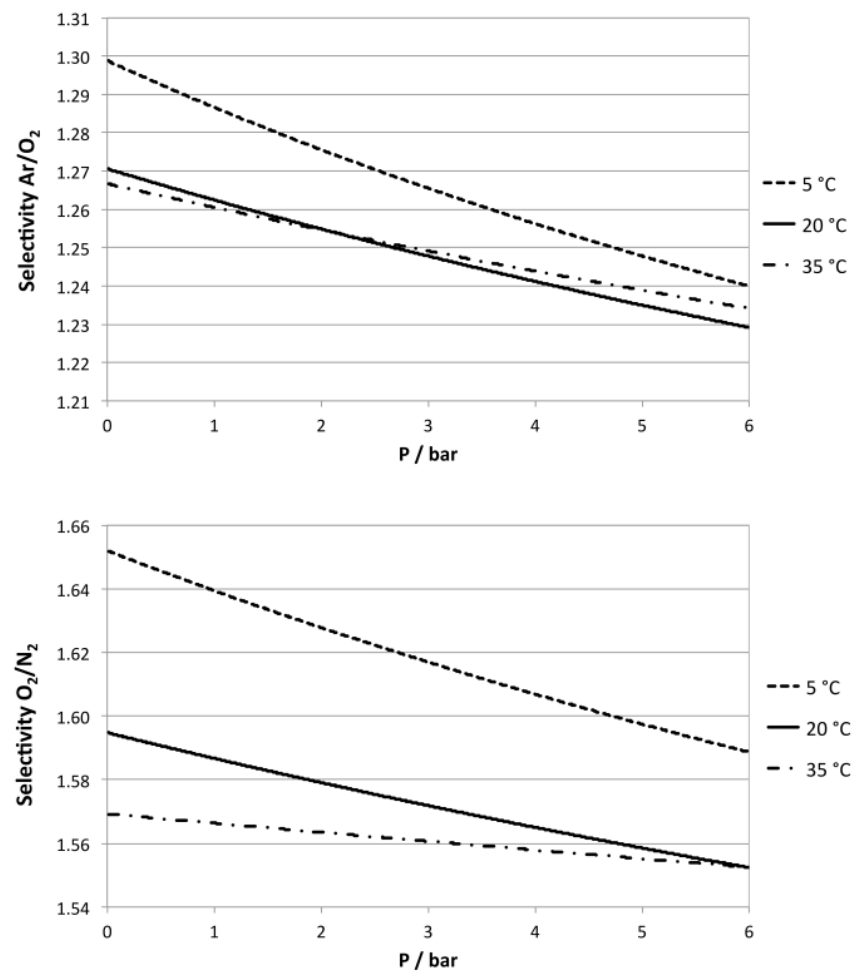

Fig. 2 Variation of $\mathrm{Ar} / \mathrm{O}_{2}$ and $\mathrm{O}_{2} / \mathrm{N}_{2}$ selectivities with pressure, for $\mathrm{VI}$, at $5{ }^{\circ} \mathrm{C}, 20^{\circ} \mathrm{C}$ and $35^{\circ} \mathrm{C}$.

The Lennard-Jones minimum width serves as a good indicator of cut-off size for sieving but is not the best measure of the most energetically favourable intermolecular distance. From the Lennard-Jones potential, this distance can be estimated as $2^{1 / 6}$ times the minimum width, that is, $0.36,0.38$ and $0.34 \mathrm{~nm}$, respectively ${ }^{51}$. It has long been known that molecules even slightly bigger than the pore/constriction experience a significantly lower adsorption potential ${ }^{51}$, which is precisely why CMSs are able to have very high kinetic selectivities. The $\mathrm{N}_{2}$ molecule is slightly bigger than the pore size of VI and IA, being thus tempting to explain the fact that $\mathrm{N}_{2}$ is the least adsorbed species because of a similar effect. This could explain both why $\mathrm{N}_{2}$ is the least adsorbed species and the most sensitive to pore size increment. However, for IV and VV, this effect should disappear and $\mathrm{N}_{2}$ become the most adsorbed species. This is not the case, so there are clearly other factors involved. The range of phenomena determining adsorption becomes much clearer upon analysis of the heats of adsorption.

\section{Heats of adsorption and influence of pore size in adsorption}

Isosteric heats of adsorption were determined using the Clausius-Clapeyron equation. Assuming ideal gas behaviour, it can be written as, 


$$
q_{s t}=-R\left(\frac{\partial \ln (P)}{\partial(1 / T)}\right)_{n}
$$

where $\boldsymbol{q}_{\boldsymbol{s}}$ is the isosteric heat of adsorption, $\boldsymbol{R}$ is the ideal gas constant and $\boldsymbol{T}$ is the absolute temperature. Having adsorption isotherms for $5{ }^{\circ} \mathrm{C}, 20^{\circ} \mathrm{C}$ and $35^{\circ} \mathrm{C}$, heats of adsorption were estimated through linearization of $\ln (\boldsymbol{P})$ vs $(\mathbf{1} / \boldsymbol{T}$ ), for a given $\boldsymbol{n}$ (when pressure values corresponding to the desired $\boldsymbol{n}$ were unavailable, they were estimated by interpolation). Results are shown in Fig. 4 Heat of adsorption as a function of the adsorbed concentration, for Ar, O2 and N2, in VI, IA, IV and VV, grouped per gas.
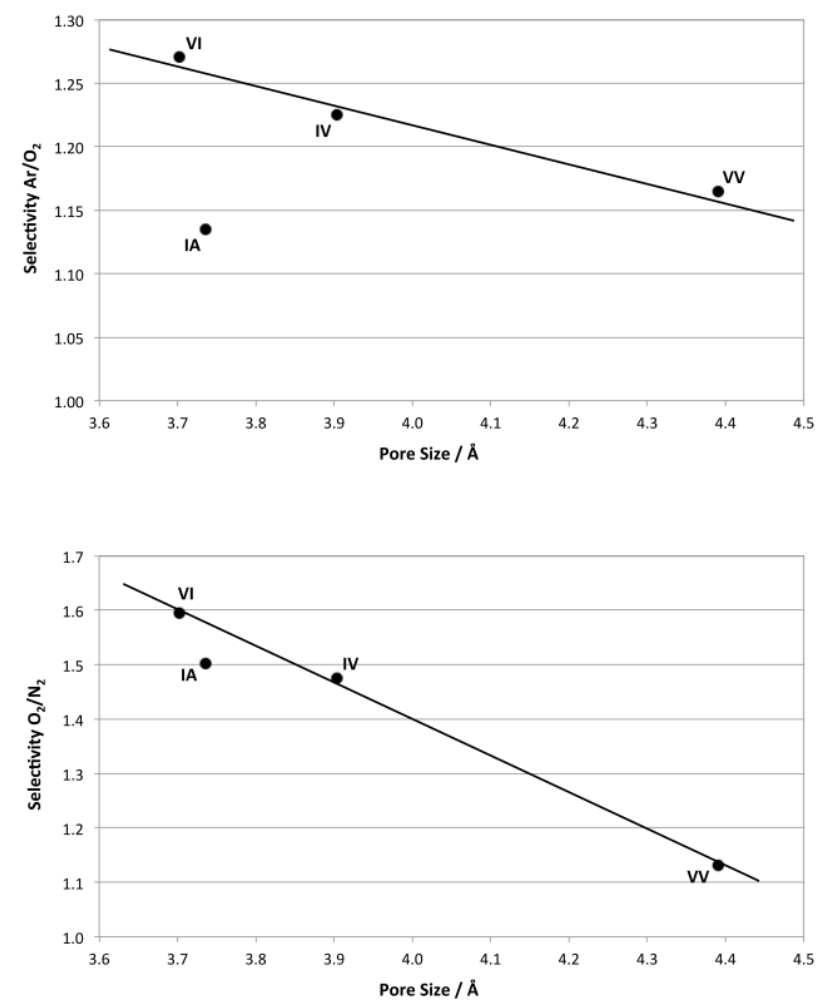

Fig. $3 \mathrm{Ar} / \mathrm{O}_{2}$ and $\mathrm{N}_{2} / \mathrm{O}_{2}$ selectivities of the four dipeptides, at $20^{\circ} \mathrm{C}$, plotted against nominal pore size. The two straight lines represent the linear decreasing trend apparent for three of the four points, in both graphs.

With the exception of $\mathrm{N}_{2}$, it is clear the heat of adsorption does not show any variation trend with adsorbed concentration, being approximately constant in the tested range. The $\mathrm{N}_{2}$ trend, however, is also not clear enough, so for it, too, a constant heat of adsorption was considered. Therefore, the heat of adsorption of each gas was obtained by averaging the values of Fig. 4 Heat of adsorption as a function of the adsorbed concentration, for $\mathrm{Ar}, \mathrm{O}_{2}$ and $\mathrm{N}_{2}$, in VI, IA, IV and VV, grouped per gas.

. These are shown in Fig. 5 Average heat of adsorption and pre-exponential constant (Eq. (5)), for Ar, $\mathrm{O}_{2}$ and $\mathrm{N}_{2}$, in VI, IA, IV and VV, grouped per gas.

. The errors were calculated from this averaging, corresponding to $95 \%$ confidence intervals.

In other materials, excluding those containing silver, the heats of adsorption of $\mathrm{N}_{2}, \mathrm{O}_{2}$ and Ar are typically in the range of $15-27 \mathrm{~kJ} / \mathrm{mol}, 13-25 \mathrm{~kJ} / \mathrm{mol}$ and $12-20 \mathrm{~kJ} / \mathrm{mol}$, respectively $28,30,38,39,41-45,52-54$. The heats of adsorption determined for VI, IA, IV and VV are close to, or below, the lower limit of these ranges. For $\mathrm{Ar}$ and $\mathrm{O}_{2}$, all the values are within the respective ranges. For $\mathrm{N}_{2}$, three out of four of those values are clearly and significantly below 15 $\mathrm{kJ} / \mathrm{mol}$, the lower limit mentioned. We were unable to find a single isosteric heat of adsorption for $\mathrm{N}_{2}$ below 15 $\mathrm{kJ} / \mathrm{mol}$ in the literature, showing that the $\mathrm{N}_{2}$ interaction with the aliphatic side-chains is exceptionally weak.

In the Henry region of a Type I isotherm, the isosteric heat of adsorption can be related to Henry's constant by the van't Hoff equation, 


$$
K_{H}=K_{H}^{\infty} \cdot \exp \left(\frac{q_{s t}}{R T}\right)
$$

where $K_{H}^{\infty}$ is the pre-exponential factor. $K_{H}^{\infty}$ expresses the entropic and capacity contributions to Henry's constant ${ }^{55}$. By using the $q_{s t}$ values obtained from the adsorption isotherms at three temperatures and the $K_{H}$ obtained from the data fitting of individual adsorption isotherms, it is possible, using Eq. (5), to calculate a $K_{H}^{\infty}$ for each isotherm. Results shown in Fig. 5 Average heat of adsorption and pre-exponential constant (Eq. (5)), for Ar, $\mathrm{O}_{2}$ and $\mathrm{N}_{2}$, in $\mathrm{VI}$, IA, IV and VV, grouped per gas.

are averages for the three temperatures, with the respective errors.
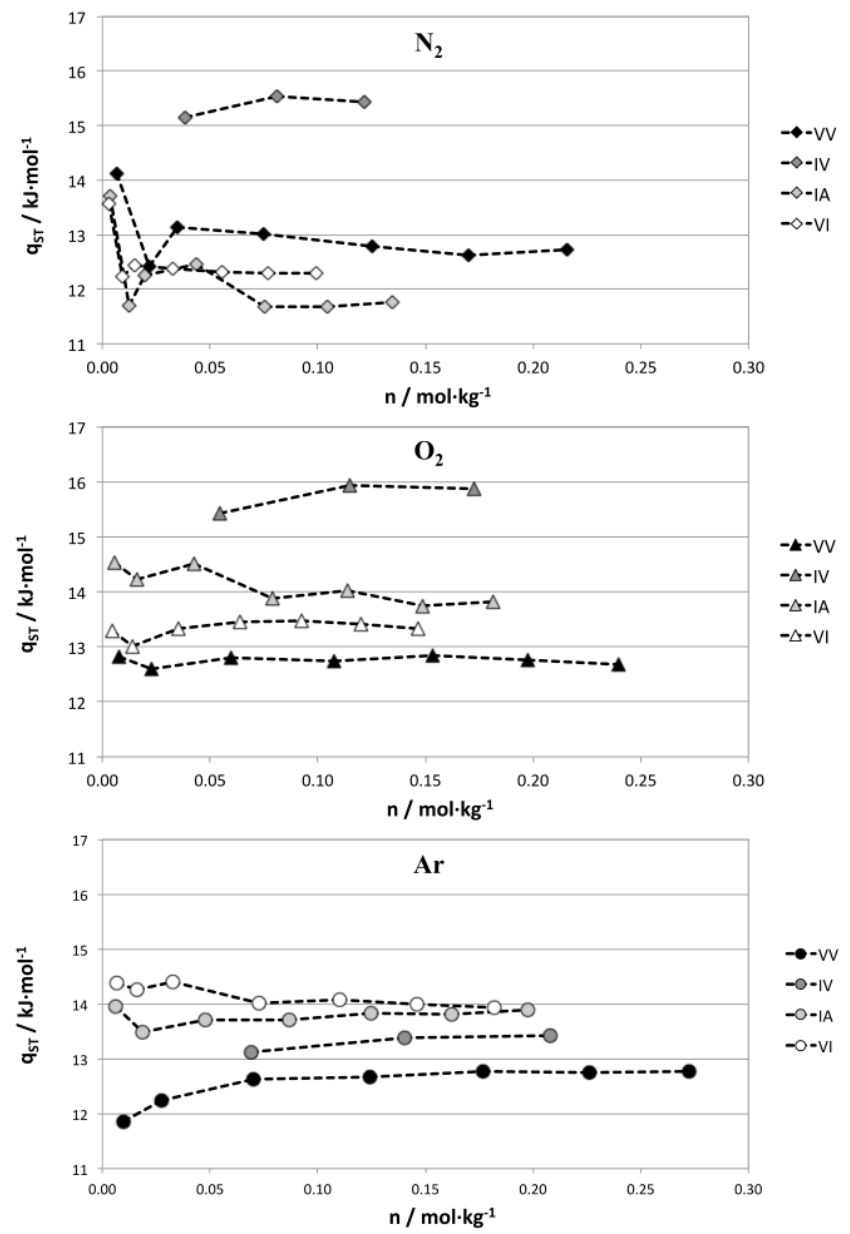

Fig. 4 Heat of adsorption as a function of the adsorbed concentration, for $\mathrm{Ar}, \mathrm{O}_{2}$ and $\mathrm{N}_{2}$, in VI, IA, IV and VV, grouped per gas.

The sequences observed for the heats of adsorption in Fig. 5 Average heat of adsorption and pre-exponential constant (Eq. (5)), for $\mathrm{Ar}, \mathrm{O}_{2}$ and $\mathrm{N}_{2}$, in VI, IA, IV and VV, grouped per gas.

Error! Reference source not found. are less regular than those observed in the adsorption isotherms. In fact, it could be argued they are highly irregular. VI is the only material having an $\mathrm{Ar}>\mathrm{O}_{2}>\mathrm{N}_{2}$ trend for heats of adsorption, equivalent to that existing in the adsorption isotherm. No other material shows it, or even any other trend. Regarding variation with pore size, only for Ar there seems to be a trend, $\mathrm{VV}<\mathrm{IV}<\mathrm{IA}<\mathrm{VI}$, precisely the opposite of that observed for the adsorption isotherms. This indicates that Ar-framework interactions diminish with increasing pore size. For $\mathrm{N}_{2}$ and $\mathrm{O}_{2}$, variation of adsorbent-adsorbate interaction intensity with pore size is not monotonic. The complex profiles obtained for $\mathrm{O}_{2}$ and $\mathrm{N}_{2}$ are very similar to each other, which could indicate that pore size increase has a similar physical effect on the two species, different from the one it has on Ar.

The polarisabilities of $\mathrm{Ar}$ and $\mathrm{O}_{2}$ are, respectively, 1.6411 and $1.5812 \AA^{3}{ }^{56}$. Both species do not have a dipole moment, but only Ar does not have a quadrupole moment. Thus, since adsorbate-adsorbent interactions can rarely be 
considered exclusively dispersive, $\mathrm{O}_{2}$ typically adsorbs more than Ar, due to the effect of its non-negligible quadrupole moment ${ }^{20,30,33,38}$. However, in the confined environment of a micropore, the polarisability of atoms and molecules may be influenced by the limited ways in which they are able to interact with the framework ${ }^{57}$, making such analyses more complicated.

Apparently, even the smallest pore $(0.37 \mathrm{~nm})$ is not too tight in order to hinder adsorption of the $0.36 \mathrm{~nm}$-wide Ar atom. Increasing pore size probably causes a decrease in the intensity of the adsorption potential well inside the pore, lowering the heat of adsorption. In the case of $\mathrm{O}_{2}$, however, there is an increase in the heat of adsorption from VI to IA and from IA to IV. Given that an $\mathrm{O}_{2}$ molecule is only slightly smaller than an Ar atom, it is unlikely the pore size increase does not contribute to decrease the adsorption potential intensity, as with Ar. It is likely that the increased rotational freedom the $\mathrm{O}_{2}$ molecules experience allows for a better matching of the pore morphology, overcoming the decreased adsorption potential effect. Between IV and the much bigger VV pore, the decreasing trend observed for $\mathrm{Ar}$ is established. For the bigger $\mathrm{N}_{2}$ molecule, there are no sensible differences between VI and IA, and only for the IV framework is the increase in the heat of adsorption clear. Besides the rotational freedom factor mentioned for $\mathrm{O}_{2}$, there may exist a small contribution from the pore size increase beyond the optimal intermolecular distance of $\mathrm{N}_{2}, 0.38 \mathrm{~nm}$. Finally, for $\mathrm{N}_{2}$ also, the big increase in pore size associated with VV significantly decreases the heat of adsorption. In fact, from IV to $\mathrm{VV}$, the heat of adsorption of all species decreases. Because the Lennard-Jones diameter/widths of $\mathrm{Ar}, \mathrm{N}_{2}$ and $\mathrm{O}_{2}$ are smaller than the nominal size of the smallest pore (VI), the influence of framework flexibility is not especially significant, with the possible exception of $\mathrm{N}_{2}$.
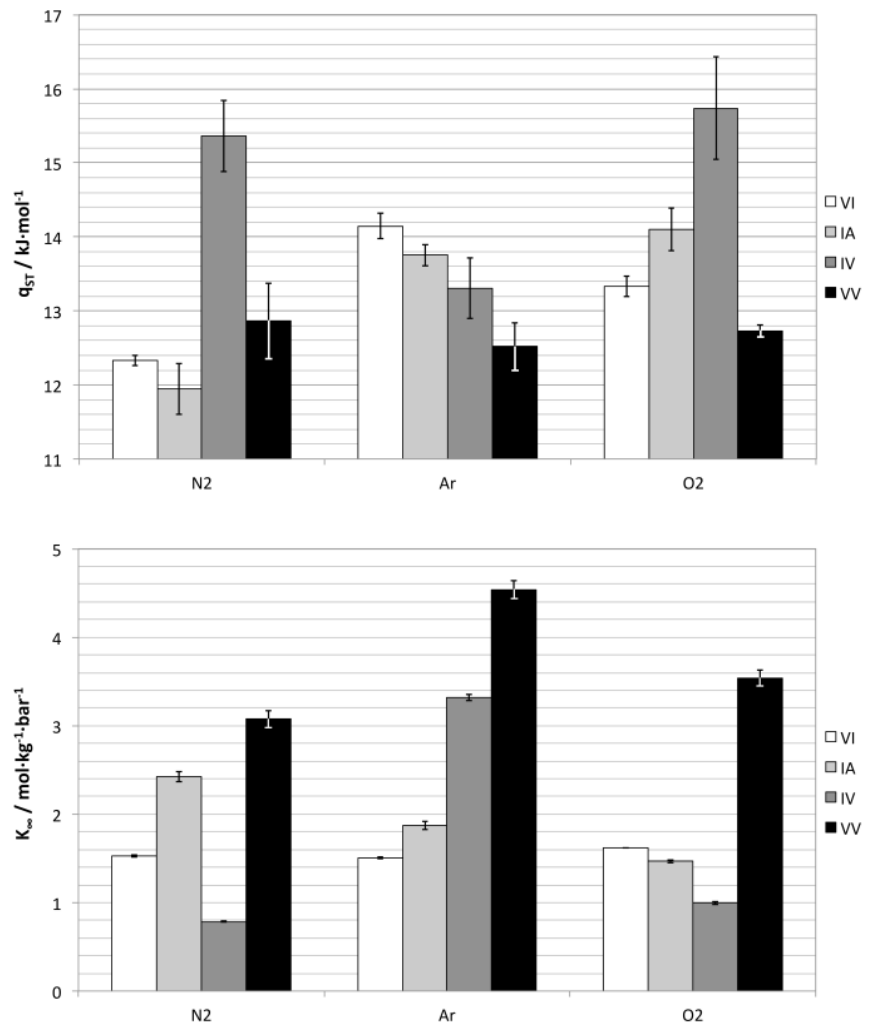

Fig. 5 Average heat of adsorption and pre-exponential constant (Eq. (5)), for $\mathrm{Ar}, \mathrm{O}_{2}$ and $\mathrm{N}_{2}$, in VI, IA, IV and VV, grouped per gas.

If compared for the same material and different species, only VI displays a clear trend in heat of adsorption variation, $\mathrm{Ar}>\mathrm{O}_{2}>\mathrm{N}_{2}$. For IA, the $\mathrm{Ar}$ and $\mathrm{O}_{2}$ values are within the error range, although both are still clearly higher than that of $\mathrm{N}_{2}, \mathrm{Ar} \approx \mathrm{O}_{2}>\mathrm{N}_{2}$. For IV, the heats of adsorption of $\mathrm{O}_{2}$ and $\mathrm{N}_{2}$ are much larger than that of $\mathrm{Ar}, \mathrm{O}_{2} \approx \mathrm{N}_{2}$ $>\mathrm{Ar}$ and, for $\mathrm{VV}$, no sensible differences exist between the three, $\mathrm{O}_{2} \approx \mathrm{Ar} \approx \mathrm{N}_{2}$.

For exclusively dispersive interactions, the heat of adsorption should only depend on the polarisabilities of the different species, so it would be expectable that Ar be more strongly adsorbed than $\mathrm{O}_{2}$. The $\mathrm{N}_{2}$ molecule has a nominal polarisability greater than the Ar atom, but since its confinement limitations are greater than those of Ar, both higher 
and lower values are reasonable. It is possible that due to their quadrupole moments, the $\mathrm{O}_{2}$ and $\mathrm{N}_{2}$ molecules bond, even if weakly, with the slightly polarised $\mathrm{H}$ atoms from the aliphatic side-chains forming the pore walls. Since the polarisability of Ar is only marginally higher than that of $\mathrm{O}_{2}$, that effect could be enough to switch the order of the heats of adsorption of the two species. An heat of adsorption of $\mathrm{N}_{2}$ similar to that of $\mathrm{O}_{2}$, in IV, may be only the reflection of the still important confinement effects having a greater impact on the bigger $\mathrm{N}_{2}$ molecule than on that of $\mathrm{O}_{2}$. This would also explain why $\mathrm{N}_{2}$ heats of adsorption are inferior to those of $\mathrm{O}_{2}$ and Ar for VI and IA, despite having greater polarisability and quadrupole moment. These confinement effects are certainly much less important in $\mathrm{VV}$, if at all significant. Therefore, it would be expectable that a $\mathrm{N}_{2}>\mathrm{O}_{2}>A$ Ar order was well established by then, which seems to not be the case.

The variation patterns observed for the $K_{H}^{\infty}$ are even harder to explain. In the four dipeptides considered, the capacities should be similar, therefore differences in $K_{H}^{\infty}$ must be explained by variations in entropic contributions. The entropy of the mobile adsorbate depends on translational, rotational and vibrational components ${ }^{58}$. For Ar, one could tentatively try to interpret the increases in $K_{H}^{\infty}$ by considering that rotational entropy is absent in Ar atoms, thus the great increases may reflect increased vibrational and translational freedom as the frameworks become more open. In the case of $\mathrm{O}_{2}$ and $\mathrm{N}_{2}$, it is possible the highly hindered non-axial rotation in VI potentiates faster translation inside the pores, while the slightly larger IA and IV allow greater rotational freedom, thus limiting translation inside the pore. This factor is the basis for some separations using microporous membranes ${ }^{59,60}$. The much bigger VV pores allow such rotational freedom that the increasing trend in $K_{H}^{\infty}$ observed for Ar is finally established.

Overall, it is astonishing how such regular patterns in amount adsorbed (adsorption isotherms), indicating equally regular free energy variation patterns, stem from such wide and irregular swings in entropy and enthalpy as those shown Fig. 5.

\section{Significance for PSA separation of air}

In spite of the extraordinary $\mathrm{Ar} / \mathrm{O}_{2}$ selectivities reported, use of hydrophobic dipeptides as PSA adsorbents is highly unlikely. Besides good selectivities, good working adsorption capacities are needed to implement any PSA separation ${ }^{18}$. The nearly linear isotherms presented allow a working adsorption capacity essentially proportional to the pressure range used in the PSA, an excellent property. However, the overall capacities are low, when compared to other materials. At ambient temperatures and for 1 bar, values of oxygen/argon adsorption between $0.1 \mathrm{~mol} / \mathrm{kg}$ and $0.2 \mathrm{~mol} / \mathrm{kg}$ are the most typical in materials that have been tested as PSA adsorbents ${ }^{22-24,27-29,32}$. These results are all significantly above the $\sim 0.05 \mathrm{~mol} / \mathrm{kg}$ obtained for Ar adsorption in VI. It thus seems these materials show very little potential as a PSA adsorbent, as long as Ag-based adsorbents remain commercially viable.

Nonetheless, that the pores of crystalline hydrophobic VA-class dipeptides can generate good $\mathrm{Ar} / \mathrm{O}_{2}$ selectivities was totally unexpected. This knowledge may be used to search for new (or otherwise) materials that combine good selectivities with good capacities. The organic materials having the $\operatorname{Ar}>\mathrm{O}_{2}>\mathrm{N}_{2}$ adsorption sequence, also observed in this work, also have very hydrophobic pores ${ }^{46,47}$, which leads us to think this is a fundamental property, together with pore size, determining the sequence. This probably results from the limited influence the quadrupolar moment of $\mathrm{O}_{2}$ has in hydrophobic pores.

The main causes of the low capacities of the materials are their low porosities and micropore concentrations. The four dipeptide frameworks considered have very similar densities, making porosity highly dependent on pore size. The crystallographic porosities of dipeptides VI, IA, IV and VV are 5.7, 6.0, 6.3 and $8.3 \%{ }^{7}$ and the micropore concentrations are $0.048,0.053,0.053$ and $0.067 \mathrm{~cm}^{3} / \mathrm{g}$, respectively. These are very small values, especially the porosities, when compared to materials used in $\mathrm{O}_{2}$-generation PSA. Ag-mordenite has been reported as having values of $17 \%$ and $0.062 \mathrm{~cm}^{3} / \mathrm{g}^{28}$, AgLiLSX has $27 \%$ and $0.118 \mathrm{~cm}^{3} / \mathrm{g}{ }^{61}$ and Ag-ETS- 10 has $38 \%{ }^{31,62}$ and $0.13 \mathrm{~cm}^{3} / \mathrm{g}^{63}$, ${ }^{64}$. The low porosity of the dipeptides is a contingent property, which does not need to exist in other materials with unidimensional pores, even for such small pores; it stems mostly from the low pore concentration existent in the dipeptides, 0.45 pores $/ \mathrm{nm}^{2}$ to 0.48 pores $/ \mathrm{nm}^{2}$. A material possessing cylindrical unidimensional pores has a geometrical limiting porosity of $78.5 \%$, corresponding, for a material with $0.4 \mathrm{~nm}$-wide pores, to $6.25 \mathrm{pores} / \mathrm{nm}^{2}$. Therefore, there is plenty of room for improvement of porosities. A material with pores having similar morphologies and chemical properties as those of the four dipeptides studied in this work, but with significantly higher porosity could, perhaps, combine both the good selectivity observed with the desired adsorption capacities. Such a material should have highly hydrophobic and less than $0.5 \mathrm{~nm}$-wide pores, and a porosity of, at least, $20 \%$. With the large numbers of organic microporous solids discovered in recent years, there are plenty of candidates to be tested ${ }^{65,66}$. 


\section{Conclusions}

Crystalline powders of hydrophobic dipeptides VI, IA, IV and VV are able to adsorb $\mathrm{N}_{2}, \mathrm{O}_{2}$ and Ar, in the sequence $\mathrm{Ar}>\mathrm{O}_{2}>\mathrm{N}_{2}$, thus displaying $\mathrm{Ar} / \mathrm{O}_{2}$ selectivity, an extremely rare result. The best $\mathrm{Ar} / \mathrm{O}_{2}$ selectivities were obtained for $\mathrm{VI}$; at $5{ }^{\circ} \mathrm{C}$ and near vacuum conditions, the $\mathrm{Ar} / \mathrm{O}_{2}$ selectivity is 1.30 , the highest ever measured in Ag-free adsorbents. Despite the good selectivity, the low capacities of the materials strongly hinder their use in PSA for $\mathrm{O}_{2}$ generation from air. At $20^{\circ} \mathrm{C}$ and 1 bar, the adsorption of $\mathrm{Ar}, \mathrm{O}_{2}$ and $\mathrm{N}_{2}$ on VI is, respectively, $0.048 \mathrm{~mol} / \mathrm{kg}, 0.038 \mathrm{~mol} / \mathrm{kg}$ and $0.023 \mathrm{~mol} / \mathrm{kg}$.

The exceptional adsorption sequence observed, $\operatorname{Ar}>\mathrm{O}_{2}>\mathrm{N}_{2}$, stems from the very small pore size of the materials. The combination of geometrical confinement effects, limitation of rotational degrees of freedom and low polarity limit both the enthalpic and the entropic contributions to the adsorption of $\mathrm{O}_{2}$ and $\mathrm{N}_{2}, \mathrm{much}$ more than that of Ar.

The low capacity of the dipeptides tested is strongly related to their low porosity, below $10 \%$ in all cases. A material with chemical and morphologically similar pores, but greater porosities, may be able to combine both the good selectivities observed with greater capacities.

\section{Acknowledgements}

This work was supported by Fundação para a Ciência e Tecnologia (projects PTDC/CTM/64191/2006 and PTDC/EQU-EQU/114944/2009) and Agência de Inovação (HPOVPSA/2010/013438). Rui Afonso thanks FCT for his PhD grant (SFRH/BD/43821/2008). We kindly thank fruitful discussions with Daniel Ferreira and Roberto Magalhães.

\section{Notes and references}

${ }^{a}$ IBMC-Institute for Molecular and Cell Biology, Rua do Campo Alegre 823, 4150-180 Porto, Portugal.

${ }^{b}$ LEPABE - Faculdade de Engenharia, Universidade do Porto, Rua Dr. Roberto Frias, 4200-465 Porto, Portugal.

${ }^{c}$ ICBAS - Instituto de Ciências Biomédicas Abel Salazar, Rua de Jorge Viterbo Ferreira 228, 4050-313 Porto, Portugal. Email: lgales@ibmc.up.pt

$\dagger$ Electronic Supplementary Information (ESI) available: [additional adsorption equilibrium results and fitting parameters]. See DOI: 10.1039/b000000x/

1. C. H. Görbitz, New J. Chem., 2003, 27, 1789-1793.

2. $\quad$ C. H. Görbitz, Chem. Eur. J., 2007, 13, 1022-1031.

3. R. Anedda, D. V. Soldatov, I. L. Moudrakovski, M. Casu and J. A. Ripmeester, Chem. Mater., 2008, 20, 2908-2920.

4. A. Comotti, A. Fraccarollo, S. Bracco, M. Beretta, G. Distefano, M. Cossi, L. Marchese, C. Riccardi and P. Sozzani, Cryst. Eng. Commun., 2013, 15, 1503-1507.

5. M. Dvoyashkin, A. Wang, S. Vasenkov and C. R. Bowers, J. Phys. Chem. Lett., 2013, 4, 3263-3267.

6. M. Dvoyashkin, H. Bhase, N. Mirnazari, S. Vasenkov and C. R. Bowers, Anal. Chem., 2014, 86, 2200-2204.

7. D. V. Soldatov, I. L. Moudrakovski, E. V. Grachev and J. A. Ripmeester, J. Am. Chem. Soc., 2006, 128, 6737-6744.

8. D. V. Soldatov, I. L. Moudrakovski and J. A. Ripmeester, Angew. Chem. Int. Ed., 2004, 43, 6308-6311.

9. A. Comotti, S. Bracco, G. Distefano and P. Sozzani, Chem. Commun., 2009, 45, 284-286.

10. I. Moudrakovski, D. V. Soldatov, J. A. Ripmeester, D. N. Sears and C. J. Jameson, Proc. Nat. Acad. Sci., 2004, 101, 17924-17929.

11. C.-Y. Cheng and C. R. Bowers, Chem. Phys. Chem., 2007, 8, 2077-2081.

12. C. H. Görbitz, M. Nilsen, K. Szeto and L. W. Tangen, Chem. Commun., 2005, 4288-4290.

13. C. H. Görbitz, Acta Crystallogr., 2002, B58, 849-854.

14. C. H. Görbitz, Cryst. Eng. Commun., 2005, 7, 670-673.

15. H. Zhang, K. Siegrist, D. F. Plusquellic and S. K. Gregurick, J. Am. Chem. Soc., 2008, 130, 17846-17857.

16. M. J. Kirschner, in Ullmann's Encyclopedia of Industrial Chemistry, ed. B. Elvers, Wiley-VCH, 2000.

17. J. G. Hansel and U. b. Staff, in Kirk-Othmer Encyclopedia of Chemical Technology, Wiley-VCH, 2005.

18. D. M. Ruthven, in Principles of Adsorption and Adsorption Processes, John Wiley \& Sons, New York, 1984 , pp. 336-379. 
19. D. Ferreira, R. Magalhães, P. Taveira and A. Mendes, Ind. Eng. Chem. Res., 2011, 50, 10201-10210.

20. N. D. Hutson, S. U. Rege and R. T. Yang, AIChE J., 1999, 95, 724-734.

21. J.-B. Kim, H. Jo, H. Yoshioka and H. Kiyama, U.S. Pat., 7,041,155, 2006.

22.

23.

24.

25.

26.

27.

28.

29.

30.

31. A. Ansón, S. M. Kuznicki, T. Kuznicki, T. Haastrup, Y. Wang, C. C. H. Lin, J. A. Sawada, E. M. Eyring and D. Hunter, Microporous Mesoporous Mater., 2008, 109, 577-580.

32. M. Shi, J. Kim, J. A. Sawada, J. Lam, S. Sarabadan, T. M. Kuznicki and S. M. Kuznicki, AIChE J., 2013, 59, 982-987.

33. S. A. Peter, A. S. Moharir and R. V. Jasra, Sep. Sci. Technol., 2011, 46, 500-506.

34. A. Ansón, S. M. Kuznicki, T. Kuznicki, B. C. Dunn, E. M. Eyring and D. B. Hunter, Sep. Sci. Technol., 2009, 44, 1604-1620.

35. A. Hazra, S. Bonakala, S. K. Reddy, S. Balasubramanian and T. K. Maji, Inorg. Chem., 2013, 52, $11385-11397$.

36. S. M. Humphrey, S. E. Oungoulian, J. W. Yoon, Y. K. Hwang, E. R. Wise and J.-S. Chang, Chem. Commun., 2008, 44, 2891-2893.

37. S. W. Rutherford and D. D. Do, Langmuir, 2000, 16, 7245-7254.

38. R. S. Pillai, S. A. Peter and R. V. Jasra, Microporous Mesoporous Mater., 2008, 113, $268-276$.

39. Y.-S. Bae and C.-H. Lee, Carbon, 2005, 43, 95-107.

40. M. C. Campo, F. D. Magalhães and A. Mendes, J. Membr. Sci., 2010, 346, 15-25.

41. S. W. Rutherford and J. E. Coons, J. Colloid Interface Sci., 2005, 284, 432-439.

42. P. Rallapalli, K. P. Prasanth, D. Patil, R. S. Somani, R. V. Jasra and H. C. Bajaj, J. Porous Mater., 2011, 18, 205-210.

43. S. A. Peter, J. Sebastian and R. V. Jasra, Ind. Eng. Chem. Res., 2005, 44, 6856-6864.

44. C. R. Reid, I. P. O'koye and K. M. Thomas, Langmuir, 1998, 14, 2415-2425.

45. G. Sethia, R. S. Pillai, G. P. Dangi, R. S. Somani, H. C. Bajaj and R. V. Jasra, Ind. Eng. Chem. Res., 2010, 49, 2353-2362.

46. P. M. Budd, K. J. Msayib, C. E. Tattershall, B. S. Ghanem, K. J. Reynolds, N. B. McKeown and D. Fritsch, J. Membr. Sci., 2005, 251, 263-269.

47. Y. Belmabkhout, G. D. Weireld and M. Frère, J. Chem. Eng. Data, 2004, 49, 1379-1391.

48. A. L. Myers, AIChE J., 2002, 48, 145-160.

49. J.-G. Jee, S.-J. Lee and C.-H. Lee, Korean J. Chem. Eng., 2004, 21, 1183-1192.

50. T. J. Giesy and M. D. LeVan, Chem. Eng. Sci., 2013, 90, 250-257.

51. J. Koresh and A. Soffer, J. C. S. Faraday I, 1980, 76, 2472-2485.

52. J. A. Dunne, M. Rao, S. Sircar, R. J. Gorte and A. L. Myers, Langmuir, 1996, 12, 5896-5904.

53. N. D. Hutson and R. T. Yang, AIChE J., 2000, 46, 2305-2317.

54. S. A. Peter, A. S. Moharir and R. V. Jasra, Ind. Eng. Chem. Res., 2010, 49, 7524-7529.

55. D. Atkinson and G. Curthoys, J. Chem. Educ., 1979, 56, 802-804.

56. F. C. Campanell, R. Battino and P. G. Seybold, J. Chem. Eng. Data, 2010, 55, 37-40.

57. E. G. Derouane, Micropor. Mesopor. Mater., 2007, 104, 46-51.

58. S. Ross and J. P. Olivier, in On Physical Adsorption, Interscience Publishers, New York, 1964, pp. 150-158.

59. K. Solvik, J. A. Weaver, A. M. Brockway and J. Schrier, J. Phys. Chem. C, 2013, 117, 17050-17057.

60. J. V. d. Mynsbrugge, J. D. Ridder, K. Hemelsoet, M. Waroquier and V. V. Speybroeck, Chem. Eur. J., 2013, 19, 11568-11576.

61. D. Ferreira, R. Magalhães, J. Bessa, P. Taveira, J. Sousa, R. D. Whitley and A. Mendes, Ind. Eng. Chem. Res., 2014, DOI: 10.1021/ie500442r. 
62. E. L. First, C. E. Gounaris, J. Wei and C. A. Floudas, Phys. Chem. Chem. Phys., 2011, 13, 17339-17358.

63. X. Liu, Q. Wang, L. Wang, G. Chu, Q. Wei and Y. Jin, Shiyou Huagong, 2012, 41, 671--676.

64. G. S. Jung, D. H. Park, D. H. Lee, H. C. Lee, S. B. Hong and H. C. Woo, Appl. Catal., B, 2010, 100, 264270.

65. R. Afonso, A. Mendes and L. Gales, J. Mater. Chem., 2012, 22, 1709-1723.

66. N. B. McKeown, J. Mater. Chem., 2010, 20, 10588-10597. 